\title{
A Case of the Right Subclavian Artery as the Last Branch of the Aortic Arch
}

\author{
By \\ Akimichi TAKemURA, Masaki MATSUMOTO and Tadaki MORI \\ Department of Anatomy, Osaka Dental University, Osaka 540 \\ (Director : Prof. Y. Ohta) \\ -Received for Publication, June 22, 1978- \\ Key Words: Anomalous case, Right subclavian artery, Aortic arch. \\ Summary. An anomalous case of the right subclavian artery arising from the \\ aortic arch as the last branch, of which the first branch was the bicarotid trunk \\ and the second the left subclavian artery, was found in a 73 year old female among \\ cadavers for student dissection in 1978. This case belonged to type $H$ of Adachi- \\ Williams-Nakagawa's classification. In addition, the right recurrent laryngeal \\ nerve was not found but there were minor variations in the azygos venous system. \\ Based on a reexamination of many original reports concerning such variations, a \\ table was prepared.
}

\section{Findings}

Cadaver: a Japanese, medium nourished, 73 year old female, cause of death unknown, subject for student dissection in 1978.

In this case, the right subclavian artery arose from the aortic arch as the last branch and passed behind the esophagus. This case belonged to type $\mathrm{H}$ of AdachiWilliams-Nakagawa's classification for variations in the branching type of the aortic arch, and also to type II of Holzapfel's classification for anomalies of the right subclavian artery arising as the last branch of the aortic arch. The structures in the vicinity of the artery were as follows.

\section{1) Aortic arch}

Three arteries arose from the aortic arch which took a normal course. They were in contact with one another in the following order (Fig. 4): a) the so-called bicarotid trunk, b) the left subclavian artery, and c) the right subclavian artery.

a) Bicarotid trunk (Figs. 1, 3, 4)

This trunk (ca. 20 and $12 \mathrm{~mm}$ in longer and shorter external diameter, respectively) arose from the superolateral wall of the aortic arch on the right side. The section of its origin was oval in shape, including its long axis in the frontal direction. The trunk ran slightly laterally and superiorly and divided into the right and left common carotid arteries about $7 \mathrm{~mm}$ superior to its origin.

The right common carotid (ca. $9.5 \mathrm{~mm}$ in external diameter at its origin) gave off a small branch (ca. $1.5 \mathrm{~mm}$ in external diameter) from its medial wall about $30 \mathrm{~mm}$ superior to its origin (Fig. $3)$. The branch appeared to be the $a$. thyreoidea ima, and ran inferomedially 
for about $10 \mathrm{~mm}$. 'Further observations, however, could not be made since it had been destroyed by the time the case was discovered.

The left common carotid artery (ca. $11.0 \mathrm{~mm}$ in external diameter at its origin) showed no variation in course and ramifications.

b) The left subclavian artery.(Figs. $1,3,4)$

This artery (ca. $11.0 \mathrm{~mm}$ in external diameter at its origin) arose from the superior wall of the convexity, the highest portion of the arch, in contact with the bicarotid trunk on the left side and ran superolaterally to the left. It curved laterally in a right angle at about $30 \mathrm{~mm}$ superior to its origin, and on the medial side of the anterior scalenus muscle gave off three branches from the same place: the left internal thoracic artery inferolaterally, the left vertebral artery superiorly, and the left thyreocervical trunk superolaterally. It then passed into a space between the scalenus anterior and medius down to beneath the clavicle.

The left vertebral artery ran superomedially to enter the transverse foramen of the 6 th cervical vertebra.

c) The right subclavian artery (Figs. $1,4,5,6$ )

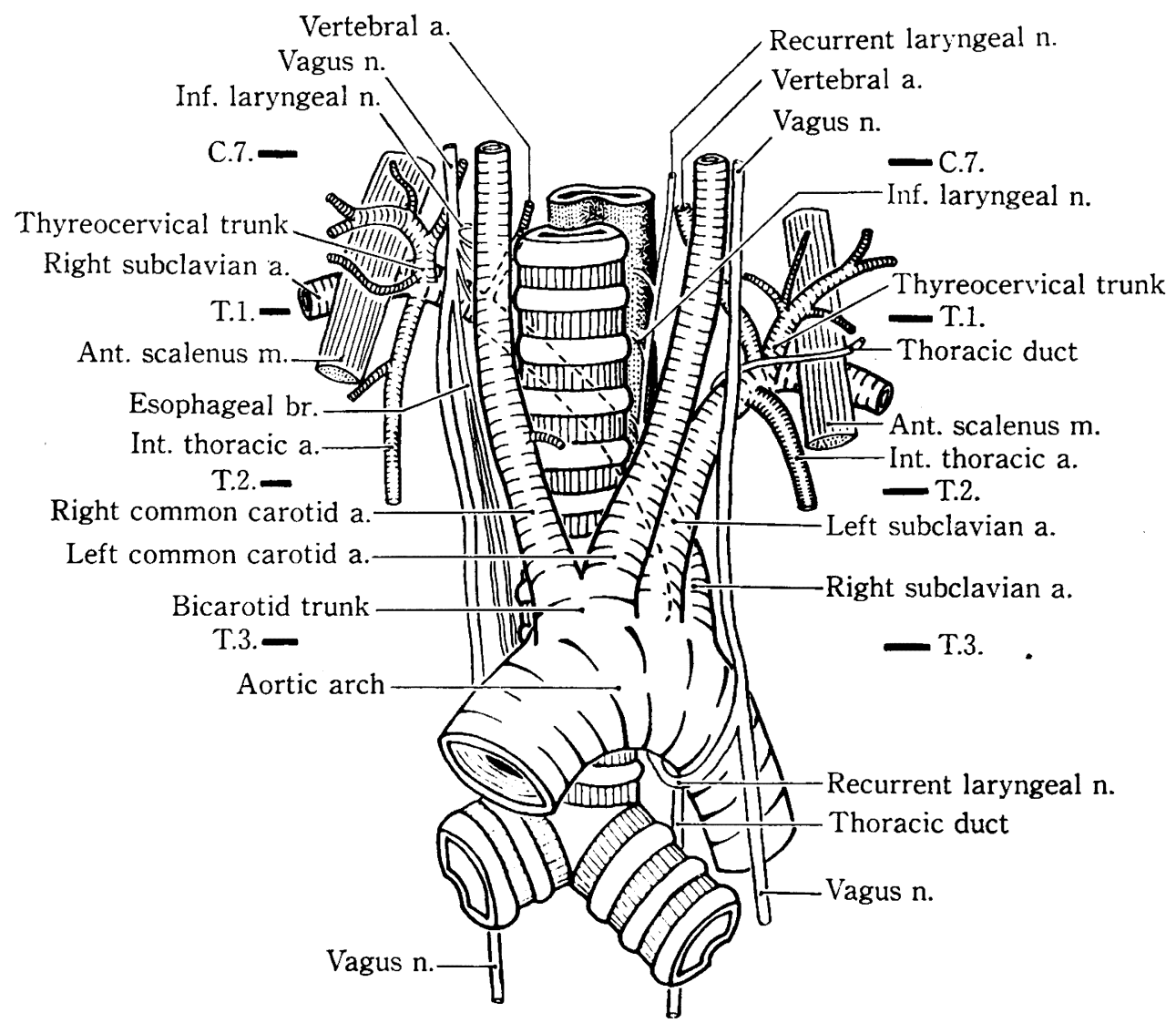

Fig. 1. Schematic drawing of the right subclavian artery and its surrounding structures. 
This artery (ca. $12 \mathrm{~mm}$ in external diameter at its origin) arose from the posterosuperior wall of the aortic arch in contact with the left subclavian posterolaterally at the level of the 3rd thoracic vertebra. No diverticulum was found near its origin. It ran upward about $10 \mathrm{~mm}$ and arched superomedially at the level of the 2 nd thoracic vertebra, and passed obliquely behind the esophagus between the 1st and 2nd thoracic vertebrae on their anterior surface at an angle of about $50^{\circ}$ against the median line. It made a depression on the posterior wall of the esophagus.

The right vertebral artery left the superior wall of the right subclavian as the first branch on the right side of the 1st thoracic vertebra, and ran slightly medially and superiorly on the anterolateral side of the 1st thoracic and 7 th cervical vertebrae to enter the transverse foramen of the 6th cervical vertebra. The right vertebral artery (ca. $3.5 \mathrm{~mm}$ in external diameter at its origin) was considerably thinner than its left counterpart (ca. $6.0 \mathrm{~mm}$ ).

The right subclavian ran superolaterally to the right and gave off the internal thoracic artery from its inferior wall inferiorly and the thyreocervical trunk from its anterior wall superiorly,

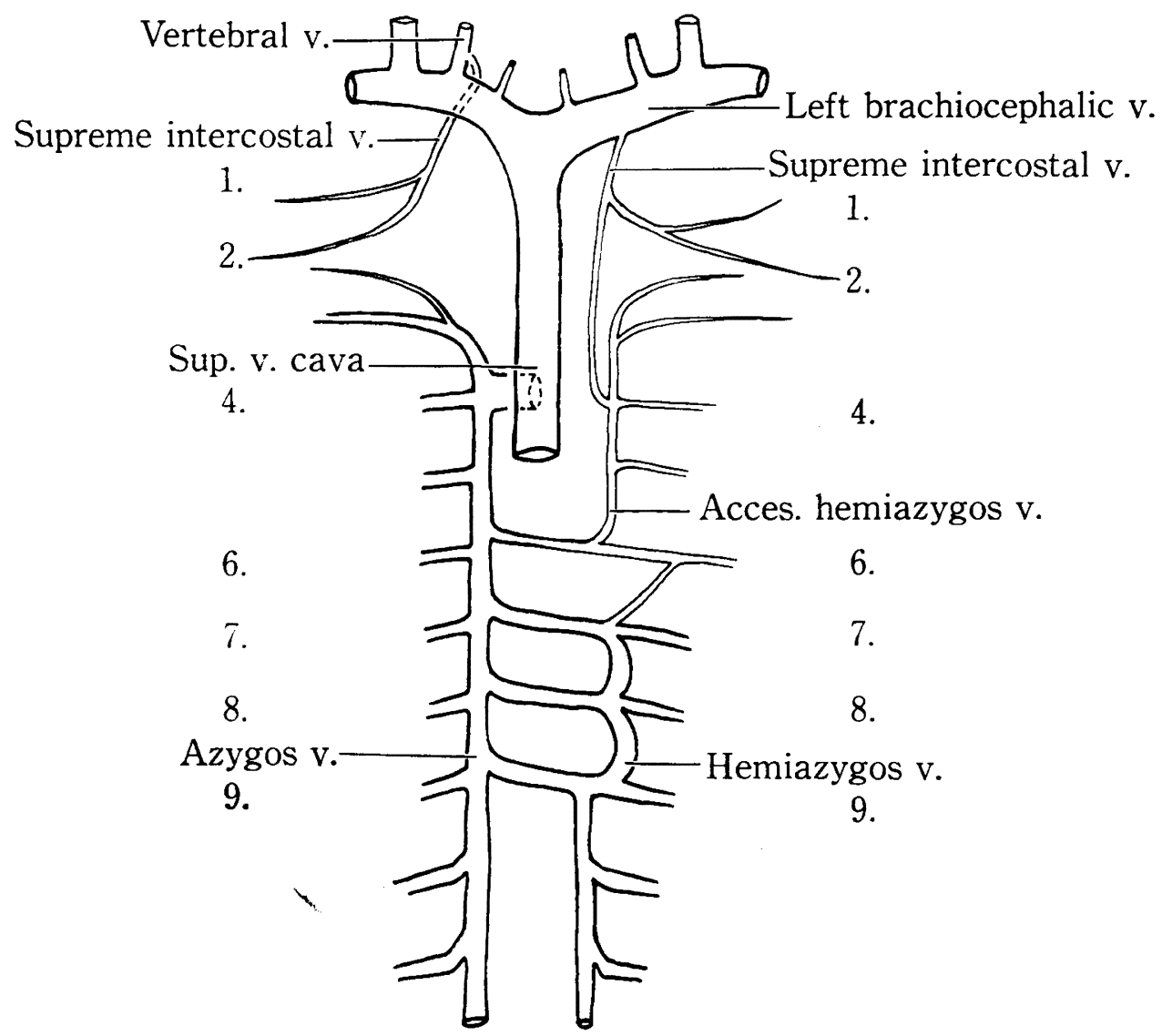

Fig. 2. Schematic drawing of the azygos venous system. Numbers : Posterior intercostal veins 
medial to the anterior scalenus muscle and about $10 \mathrm{~mm}$ distal to the origin of the right vertebral. The right subclavian arched inferolaterally posterior to the muscle down to beneath the clavicle.

2) Thoracic duct (Figs. 1, 3, 5)

This duct ascended between the thoracic aorta and the azygos vein, anterior to the vertebral column on the right side, and obliquely behind the esophagus at the level of the 6 th thoracic vertebra superomedially. It ran superiorly on the left side of the vertebral column and came behind the aortic arch. It bent superolaterally posterior to the origin of the left subclavian artery and passed anterior to the origin of the left vertebral artery to pour into the left venous angle.

3) Recurrent laryngeal nerve (Figs. 1,6)

The right recurrent laryngeal nerve was not found. Instead, the inferior laryngeal nerve which left the right vagus nerve about $10 \mathrm{~mm}$ superomedial to the origin of the right thyreocervical trunk, was distributed to the larynx directly. Simultaneously, several esophageal branches left the nerve inferiorly.

The left recurrent laryngeal nerve hooked around the arotic arch.

\section{4) Sympathetic nerve trunk}

The stellate ganglion and the ansa subclavia on both sides were located in the lateral of the vertebral column and the superomedial of the origin of the vertebral arteries.

5) Azygos venous system (Fig. 2)

a) Azygos vein

This vein ascended on the right side of the thoracic vertebrae, receiving the right 2nd to 12th posterior intercostal veins. It poured into the posterior wall of the superior vena cava at the level of the 4 th thoracic vertebra. The right supreme "intercostal vein receiving the right 1 st and 2 nd intercostal veins, ascended in the anterolateral of the 1st thoracic vertebra and passed behind the right subclavian artery up to medial to the origin of the right vertebral artery to pour into the right vertebral vein.

b) Hemiazygos vein

This vein, thinner than the azygos vein, ascended on the left side of the vertebral column receiving the left 6 th to 12 th posterior intercostal veins, and poured into the azygos with three branches which ran transversely in front of the 7 th, 8 th and 9 th thoracic vertebrae. The left 6 th intercostal vein communicated with the hemiazygos and the accessory hemiazygos veins.

c) Accessory hemiazygos vein

This vein, considerably thinner than the hemiazygos, receiving the left 2nd to 6 th intercostal veins descended on the left side of the vertebral column and poured into the azygos vein passing anterior to the 6 th thoracic vertebra.

The left supreme intercostal receiving the left 1 st and 2 nd intercostal veins ascended on the left side of the rertebral column to pour into the inferior wall of the left brachiocephalic vein, and communicated with the accessory hemiazygos via a vein at the level of the 4 th intercostal vein.

\section{Discussion}

The case of the right subclavian artery as the last branch of the aortic arch, corresponding to type $G$ of Adachi's classification (1928), which is called the pattern $\mathrm{E}$ on the classification of $\mathrm{De}$ Garis et al. (1933), has not been rare at the present time. Since Suzuki (1894) reported as the first case of type $G$ mentioned above in the Japanese, 84 reports in adults, fetuses and neonates have been 
encountered in the anatomical field; 53 adults including two cadavers whose ages are unknown, 31 fetuses and neonates. So, the present case may be ranked as the 85 th case of type $G$ in the Japanese as far as the present authors have known. Hanai et al. (1963) reported such a case in a 9 month old fetus and the present report was the second case at the same university.

The present authors have read extensive reports referring to the case of type $G$ in the Japanese, including the type $\mathrm{H}$ and type $\mathrm{CG}$ of the AdachiWilliams-Nakagawa's classification. Such reports have increased in number since Fujimoto et al. and Nishimura et al. reported successively in 1963 . As a result, there were great differences of opinion among the researchers about the interpretation both in the number and in the order of the cases so far reported.

Taniguchi (1934) once prepared a table, and his case was compared with 9 cases he had read. Likewise Nakagawa (1939), Adachi (1941), Omochi et al. (1942), Arakawa et al. (1958), Ueki et al. (1962), Fujimoto et al., Nishimura et al., Tsuji et al. (1965), Morita et al. (1967) and Okumura et al. (1974) have made similar tables one after another. The items in the tables occasionally differed to some extent from the descriptions in the reports. Some of the discrepancies have been partly corrected in later reports, but others have introduced new errors. Accordingly, the present authors attempted to reexamine the contents of the original reports or tables carefully, ranging from the 1st case to our own case, and finally prepared the table attached to this report after correcting items that appeared to be errors.

The present case of the type $G$ of Adachi's classification was the first case in approximately 470 adult cadavers for student's dissection at this university and showed $0.2 \pm 0.2$ per cent in frequency. The incidence of this anomalous case in the Japanese was 57 cases in ca. 12153 cadavers $(0.47 \pm 0.06$ per cent). These 57 cases comprised 30 cases in 4050 fetuses and neonates $(0.74 \pm 0.13$ per cent), and 27 cases in ca. 8103 adults $(0.33 \pm 0.06$ per cent). The incidence of the former is about twice as much as the latter and the difference between the two was statistically significant at less than one per cent level.

The authors wish to express their thanks to Professor Y. Ohta and Assistant Professor T. Tokioka for their advice in the preparation of this report.

\section{References}

1) Adachi, B.: Beiträge zur Anatomie der Japaner. XIII. Die varietäten der Verzweigung des Arcus aortae. Z. Morph. Anthrop., 18: 227-240, 1914.

2) Adachi, B.: Das Arteriensystem der Japaner. Bd. 1, Maruzen Co., Kyoto, 2941, 1928.

3) Adachi, B.: Über die Arteria subclavia dextra als letzter Ast des Arcus aortae bei den Japanern. Z. Morph. Anthrop., 39 : 443-479, 1941.

4) Ajiki, H., S. Nakae, T. Uedo, Y. Asai \& T. Wada: A successful surgery for dysphagia lusoria due to right aberrant subclavian artery in an infant. Jap. J. Pediat. Surg. and Med., 6 : 269-272, 1974. (in Japanese)

5) Arakawa, H., Y. Kitayama \& T. Azuma : One case of the right subclavian artery as the last branch of the aortic arch. Reports from Dept. of Anat., Mie Pref. Univ. Sch. of Med., $3:$ 95-98, 1958. (in Japanese)

6) Aso, M.: Ein Fall der Art. subclavia dextra als letzter Ast des Arcus aortae. Acta Anat. Nippon., 4 : 1399-1403, 1932. (in Japanese)

7) De Garis, C.F.: Modes of origin of the subclavian artery in whites and negroes, with report of a case of anomalous right subclavian artery. Anat. Rec., 26 : 235- 
240, 1923.

8) De Garis, C.F., I.H. Black \& E.A. Riemenschneider: Patterns of the aortic arch in American white and negro stocks, with comparative notes on certain other mammals. J. Anat., $67:$ 599-619, 1933.

9) Fujii, H., S. Takai \& H. Isono: A case of the abnormal origin of the right subclavian artery. Acta Schol. Med. Gifu, 21 : 123-127, 1973.

10) Fujimoto, T. \& N. Kato: A case of the right subclavian artery passing behind the eosophagus. Acta Anat. Nippon., 38 : 311-320, 1963. (in Japanese)

11) Hanai, H., A. Ryumon, K. Kamakura \& S. Kaneko: An anomalous case of $A$. subclavia dextra rising from Arcus aortae as the last branch. Okajimas Fol. anat. jap., $39:$ 31-37, 1963.

12) Hasebe, K.: Ein Fall der A. subclavia dextra als letzter Ast des Aortenbogens. Hokuetsu Igakkai Kaihou, 188: 253-260, 1912. (in Japanese)

13) Hirako, G.: Zwei Fälle der Arterienvarietäten. Tokyo J. Med., 33 : 280-285, 1919. (in Japanese)

14) Holzapfel, G.: Ungewöhnlicher Ursprung und Verlauf der Arteria subclavia dex. tra. Anat. Hefte, 12: 369-523, 1899.

15) Ichimaru, K.: Ein Fall von Anomalie der A. subclavia dextra als letzter Ast des Aortenbogens. Nippon Iji Shuhou, 1945: 1611-1615, 1933. (in Japanese)

16) Inoue, S., M. Sakai, T. Kitamura, M. Nakane, K. Miyata, M. Mori \& A. Kanai : A case report of an aberrent right subclavian artery and survery of the literatures. Jap. J. Thoracic Surg., 29: 894-897, 1976. (in Japanese)

17) Isono, H., S. Sakurai, H. Fujii \& S. Aoki: The aberrant right subclavian artery as the last branch of the aortic arch. Acta Schol. Med. Gifu, 18: 891899, 1971.

18) Isono, H., N. Ishizaki, K. Hayashi, S. Takai, T. Yamahira \& S. Yamada: An anomalous case of the right subclavian artery as the last branch of the aortic arch. Acta Schol. Med. Gifu, 25, 13-16, 1977. (in Japanese)

19) Jinguji, Y. \& A. Takisawa: Two ano- malous cases of the right subclavian artery as the last branch of the aortic arch. Kitakanto Med. J., 26: 387-390, 1976. (in Japanese)

20) Kaneko, K., M. Akita, K. Okabe \& R. Osaki: A case of the right subclavian artery as the last branch from the aortic arch in a Japanese male cadaver. J. Saitama Med. Sch., 2: 161-164, 1975. (in Japanese)

21) Kasai, T.: Topographic changes of the surrounding structures of the arch of aorta in various anomalies of aorta in man. Acta Anat. Nippon., 37: 275-292, 1962.

22) Kasai, T., S. Aiyama, S. Kihara \& G. Takahashi: Studies on the anomalies of the arch of aorta in human fetuses or newborns. Acta Anat. Nippon., 44 : 213221, 1969.

23) Kasai, T. \& S. Chiba: Anomalies of the aortic arch viewed from the anatomical standpoint. (I) A case of the aberrant right subclavian artery and some problems unsolved (abstract). Acta Anat. Nippon., $54: 48,1979$. (in Japanese)

24) Kato, S., S. Morita, S. Nakajima \& Y. Kaito: Three cases of the right subclavian artery rising from the aortic arch as the last branch (abstract). Acta Anat. Nippon., 50: 281, 1975. (in Japanese)

25) Kato, S.: Corrosion-anatomical studies on the arterial system of the Japanese fetuses : Aortic arch and external carotid artery. Tokyo Jikeikai Med. J., 91 : 158170, 1976. (in Japanese)

26) Kawana, E., S. Hasegawa \& .T. Hiyama : One case of the right subclavian artery as the last branch of the aortic arch. J. Chiba Med. Soc., 36: 710-713, 1960. (in Japanese)

27) Kidani, M. \& S. Noto: A case of aberrant right subclavian artery associated with VSD, PDA and severe pulmonary hypertension. J. Jap. Ass. for Thoracic Surg., 23 : 1349-1353, 1975. (in Japanese)

28) Kikuchi, S.: Über eine Anomalie der Arteria subclavia dextra bei einer Japanerin. Arb. Anat. Inst. Sendai, $17:$ 153157, 1935. 
29) Kitagawa, T. \& T. Yukishita: Unu Kazo de la dekstra subklavikla arterio, originanta neordinare el l'aorto (abstract). Acta Anat. Nippon., 37: 31, 1962. (in Japanese)

30) Kitagawa, T., M. Tezuka \& T. Yukishita: Du kazoj de A. subclavia dextra, kiu originas anomale el l'aorto. Nihon Univ. Med. J., 28 : 323-329, 1969. (in Japanese)

31) Kobayashi, S.: A case of the paired inferior venae cavae with the abnormal origin of the right subclavian artery. Acta Anat. Nippon., 43: 177-180, 1968. (in Japanese)

32) Kodama, K.: Two cases of the right subclavian artery as the last branch from the aortic arch. Mitt. med. Akad. Kioto, 14: 961-964, 1935.

33) Masuko, S. \& Y. Shimada: A case of an anomalous origin of the right sub. clavian artery. J. Chiba Med. Soc., 52 : 43-44, 1976. (in Japanese)

34) Miura, M.: Anomalien der Gefäßstämme. Tokyo J. Med., 11:817-819, 1897. (in Japanese)

35) Miyashita, K.: An anomalous case of the right subclavian artery. Manshuu Igaku Z., 22 : 711-716, 1935. (in Japanese)

36) Miyazaki, M., T. Kuhara, N. Mitsuhashi \& T. Sayanagi: Über einen Fall der Verästelungsanomalie des Arcus Aortae. J. Kurume Med. Ass., 22 : 505-510, 1959. (in Japanese)

37) Mori, Y.: Der Aortenbogen und seine Äste bei japanischen Feten. Acta Anat. Nippon., 17: 159-168, 1941. (in Japanese)

38) Morita, M.: Ein Fall der A. subclavia dextra als letzter Ast des Aortenbogens. Acta Med. (Igaku Kenkyu), 9 : 2007-2014, 1935. (in Japanese)

39) Morita, S. \& S. Kato: One case of the right subclavian artery as the last branch of the aortic arch (abstract). Acta Anat. Nippon., 42: 5, Supplement, 3,1967 . (in Japanese)

40) Morita, S., S. Kato, T. Oda \& M. Tanaka: An anomalous case of a. subclavia dextra rising from the aortic arch as the last branch. Tokyo Jikeikai Med. J., $85: 674-681,1970$. (in Japanese)
41) Nakagawa, M.: Über die Arteria subclavia dextra als letzter Ast des Aortenbogens. J. Juzen Med. Soc., 44 : 208-215, 1939. (in Japanese)

42) Nakagawa, M.: Über die Typen der Verzweigung des Aortenbogens. J. Juzen Med. Soc., 44 : 243-259, 1939. (in Japanese)

43) Nakanishi, T.: One case of the right subclavian artery as the last branch of the aortic arch. Fukushima Med. J., 14 : 159-164, 1964. (in Japanese)

44) Nii, K., N. Honda \& T. Ishida: Ein Fall von Anomalie der A. subclavia dextra. Arch. Dept. of Anat., Kanazawa Med. Sch., 13: 47-51, 1933. (in Japanese)

45) Nishimura, S. \& Y. Kubota: Über einen Ausnahmefall der Arteria subclavia dextra als Ramus terminalis des Arcus aortae. J. Kurume Med. Ass., 26 : 375-380, 1963. (in Japanese)

46) Numazawa, K., M. Moriuchi \& T. Nishiyama: One case of the right subclavian artery as the last branch of the aortic arch. Acta Inst. Anat. Niigata, 31, Supplement: 1-4, 1954. (in Japanese)

47) Ogura, K., K. Tanuma, M. Asakawa, M. Kitazawa \& F. Kikkawa: A case of dwarf associated with anomalies in the origin of the A. subclavia dextra and genital organs (abstract). Acta Anat. Nippon., 53: 480, 1978. (in Japanese)

48) Ohmori, T.: One case of the right subclavian artery as the last branch of the aortic arch (abstract). J. Kyusyu Dent. Soc., 13:675, 1959. (in Japanese)

49) Okamoto, N., T. Ikeda \& A. Inoue : Aortic arch variations observed in 3154 fetuses and newborns. Proc. Res. Inst. for Nuc. Med. Biol., 4 : 63-65, 1963. (in Japanese)

50) Okumura, K. \& T. Fujimoto: A case of anomalous right subclavian artery passing behind the esophagus with a rare variation of the thoracic duct. Acta Anat. Nippon., 49: 179-183, 1974. (in Japanese)

51) Omochi, S. \& Y. Hayashi : One case of the right subclavian artery as the last branch of the aortic arch. Mitteil. d. 
Med. Gessell. zu Osaka, 41: 3-8, 1942. (in Japanese)

52) Saigo, S., K. Sakamoto, F. Sato, E. Sata \& T. Fujimoto: An anomalous case of the right subclavian artery: Type $G$ by Adachi (abstract). Acta Anat. Nippon., $44: 140,1969$. (in Japanese)

53) Sakaguchi, N. \& Y. Kikuchi: Unu Kazo de la dekstra subklavikla arterio kiel la fina branco el aorta arko (abstract). Acta Anat. Nippon., 39: 116, 1964. (in Japanese)

54) Sakai, A.: A rare anomalous case of the right subclavian artery as the last branch of the aortic arch with the bilateral superior venae cavae and the high division of the right radial artery in the adult (abstract). Acta Anat. Nippon., $39: 116-117,1964$. (in Japanese)

55) Shimada, K.: (cited by Adachi (2), 1928), 1924.

56) Shimada, Y. \& U. Fukuyama: An anomalous case of the right subclavian artery as the last branch of the aortic arch. Acta Anat. Nippon., $46: 400-402$, 1971. (in Japanese)

57) Shimamoto, O.: One case of the right subclavian artery from the aortic arch as the last branch. Nagasaki Med. J., $26: 352-355,1951$. (in Japanese)

58) Shirakata, S., S. Nakaji, T. Hara et al. : A case of aberrant right subclavian artery. Jap. J. Thoracic Surg., $27: 729-$ 732, 1974. (in Japanese)

59) Shoumura, S., T. Yamahira, N. Ishizaki, K. Hayashi \& H. Isono: An abnormal case of the right subclavian artery as the last branch of the aortic arch. Acta Schol. Med. Gifu, 27: 36-39, 1979. (in Japanese)

60) Sumida, N. \& J. Ihara: A case of the kinking of the aortic arch with the aberrant right subclavian artery. J. Pediat. Pract., $34: 840-844$, 1971. (in Japanese)

61) Suzuki, B.: Ein Fall von Missbildung der Arteria subclavia dextra. Tokyo J. Med., $8: 1031-1035$, 1894. (in Japanese)

62) Taniguchi, Y.: Ein Fall der anomali. schen Verzweigungsform des Arcus aortae, begleitend die A. subclavia dextra als der letzte Ast. J. Osaka Med. Coll., 2 : 107-112, 1935. (in Japanese), The collected papers of Dept. of Anat., Osaka Dent. Coll., Vol. 1: 31-38, 1960.

63) Taniie, S., K. Kaneko \& F. Kikkawa: One case of the right subclavian artery as the last branch of the aortic arch (abstract). J. Nippon Med. Sch., 39: 525, 1972. (in Japanese)

64) Taniie, S., M. Asakawa, F. Kikkawa \& N. Matsuo: An anomalous case of the right subclavian artery as the last branch of the aortic arch (abstract), J. Nippon Med. Sch., 43: 362-363, 1976. (in Japanese)

65) Tsuji, S., T. Iida \& M. Hara: Über eine Varietät der Verzweigung des Arcus aortae. J. Kyoto Pref. Med. Univ., 74 : 288-295, 1965. (in Japanese)

66) Ueki, H. \& T. Toshibe: One case of the right subclavian artery as the last branch of the aortic arch. Studies from Dept. of Anat., Iwate Med. Coll., 10: $67-71,1962$. (in Japanese)

67) Umezue, Y.: Anomaly of the branches of the aortic arch. Kyushu Igaku Z. 2: 473-475, 1937. (in Japanese)

68) Umezue, Y.: Verzweigungsformen des Aortenbogens an Kyusyu-Japaner. Acta Med. (Igaku Kenkyu), 16 : 905-916, 1942. (in Japanese)

69) Williams, G.D., H.M. Aff, M. Schmeckebier, H.W. Edmonds \& E.G. Graul: Variations in the arrangement of the branches arising from the aortic arch in American whites and negroes. Anat. Rec., 54 : 247-251, 1932.

70) Williams, G.D. \& H.W. Edmonds : Ibid. (a second study). Anat. Rec., 62: 139146, 1935.

71) Yamamoto, K., J. Higashino, M. Yamada, M. Abe \& A. Takakusu: A case of the right subclavian artery as the last branch of the aortic arch. J. Nara Med. Ass., $28: 19-25$, 1977. (in Japanese)

72) Yanai, K., T. Abe \& M. Oh: An anomalous case of the right subclavian artery as the last branch of the aortic arch (abstract). Acta Anat. Nippon., $54(2): 105,1979$. (in Japanese)

73) Yoshida, Y. \& U. Fukuyama: A case 
of an anomalous origin of the right subclavian artery and analysis of the right recurrent nerve fibers. J. Chiba Med. Soc., 51: 195-199, 1975. (in Japanese)

74) Yoshitomi, M., E. Kanamaru, G. Ohtomo, K. Ishibashi, H. Saiki \& T. Ariyoshi : An anomalous case on four branches of the aortic arch. J. Kurume Med. Ass., $40: 853-855,1977$. (in Japanese)

75) Yoshizuka, M., K. Sakai, Y. Katsume, A. Hirotsu, T. Nonaka \& K. Tokuyama : An anomalous case of four branches of the aortic arch. J. Kurume Med. Ass., $41: 274-277,1978$. (in Japanese)

\section{Addendum}

Since the present paper was submitted for publication the following two reports have been published:

Yamazaki, M.: A case of the retro-esophageal right subclavian artery as the last branch of the aortic arch (abstract). Acta Anat. Nippon., $54: 263,1979$. (in Japanese)

Kato, S.: Branches of the aortic arch (abstract). Acta Anat. Nippon., $54: 265$, 1979. (in Japanese) 


\section{Explanation of Figures}

Fig. 3. Anterior view. The so-called bicarotid trunk arises from the aortic arch. The a. thyreoidea ima (?) leaves the right common carotid artery. ca. $\times 0.8$

Fig. 4. Plastic cast of the aortic arch and three arteries arising from it. ca. $\times 0.6$

Fig. 5. Anterior view. The right subclavian artery passes obliquely between the esophagus and the vertebral column. ca. $\times 0.7$

Fig. 6. The vicinity of the thyreocervical trunk of the right subclavian artery. The right vagus nerve supplies several branches to the larynx directly and several esophageal branches inferiorly. ca. $\times 1.1$

Key to Abbreviations

B : Esophageal branches

C : Cervical vertebrae

D : Thoracic duct

E : Esophagus

G: Thyroid gland

L : Inferior laryngeal nerve

$P$ : Phrenic nerve

$R$ : Recurrent laryngeal nerve

$\mathrm{S}$ : Anterior scalenus muscle

$T$ : Trachea

$\mathrm{V}$ : Vagus nerve
aa: Aortic arch
bt: Bicarotid trunk
im: A. thyreoidea ima (?)
it: Internal thoracic artery
Ic: Left common carotid artery
Is: Left subclavian artery
Iv: Left brachiocephalic vein
rc: Right common carotid artery
rs: Right subclavian artery
sv: Superior vena cava
tt : Thyreocervical trunk 


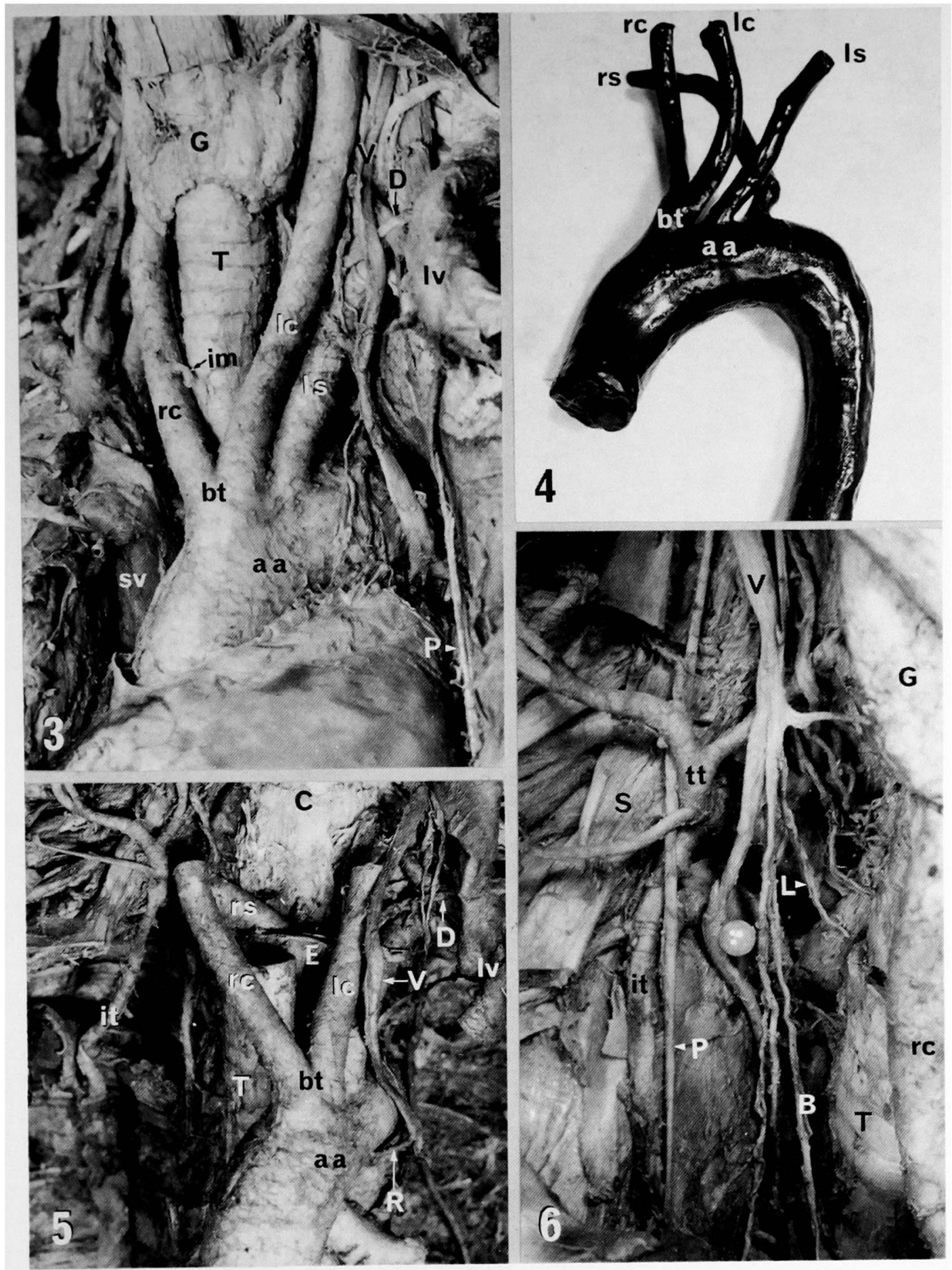

A. Takemura, M. Matsumoto and T. Mori 